\title{
Variações intraespecíficas de taquizoítos do Toxoplasma gondii (Apicomplexa: Toxoplasmatinae) isolados de uma infecção natural e comparadas frente a cepa congênita*
}

\author{
Intraspecific variations of tachyzoites of Toxoplasma gondii (Apicomplexa: \\ Toxoplasmatinae) isolated from a natural infection, and its comparition with \\ congenital strain
}

\author{
Walter Flausino," Cleber Oliveira Soares,"' Ronald Bastos Freire, "' Carlos Wilson Gomes Lopes"
}

\begin{abstract}
Resumo
Estudou-se as variações protéicas de taquizoítos de uma amostra acistogênica de Toxoplasma gondii isolada de uma galinha naturalmente infectada, e comparada a cepa congênita, mantidas em camundongo albino. A avaliação eletroforética revelou perfis protéicos distintos, embora o grupo analisado compartilhe identicamente oito moléculas (P30; 34,7; 43; 50; 58; 67; 80 e P97). A análise densitométrica revelou picos compatíveis com a eletroforese, existindo diferenças a nível da concentração protéica para cada molécula. As variações intraespecíficas observadas sugerem uma possível adaptação do parasita ao hospedeiro.
\end{abstract}

Palavras-chave: Toxoplasma gondii; camundongo albino; isolado de galinha; taquizoítos; cepa congênita.

\section{Introdução}

Toxoplasma gondii (Nicolle e Manceaux, 1909), agente etiológico da toxoplasmose, encontra-se em ampla variedade de espécies de mamíferos e aves, sendo de distribuição cosmopolita (Frenkel, 1990). As aves têm sido consideradas como animais portadores do $T$. gondii em ambientes peridomiciliares (Ruiz e Frenkel, 1980).

Os determinantes antigênicos do T. gondii incluem componentes moleculares os quais são correlacionados à biologia celular do parasito, à indução de resposta imune, e aos estágios da doença; sendo que os antígenos de superfície de taquizoítas são de grande importância, pois além de caracterizarem a adesão, reconhecimento da célula hospedeira e invasão, representam a resposta imunológica primária do hospedeiro (Kasper et al., 1983; Decoster et al., 1988).

Apesar de existirem variações morfológicas e antigênicas entre os estágios do ciclo evolutivo deste parasito, principalmente nas suas formas invasivas tais como os bradizoítas nos cistos, os taquizoítas sistêmicos e os esporozoítas dos oocistos (Dubey et al., 1970 ; Frenkel et al., 1972), muitas amostras de T. gondii têm sido isoladas em diferentes hospedeiros, embora com formas semeIhantes, têm-se observado variações a nível morfológico
(Medeiros e Lopes, 1996), biológico, sorológico e imunológico (Ware e Kasper, 1987 ; Verhofstede et al., 1988 ; Charif et al., 1990).

Assim, o presente trabalho tem como objetivo avaliar as variações protéicas entre as amostras acistogênica de T. gondii, isoladas a partir de cérebro e coração de uma galinha naturalmente infectada, comparando-as com a cepa " $C$ ", isolada de um caso humano congênito e mantidas em camundongos.

\section{Material e métodos}

\section{Origem dos taquizoítos estudados}

As amostras de T. gondii isoladas de cérebro e coração de uma galinha naturalmente infectada foram obtidas de acordo com Medeiros e Lopes (1996). Para efeito de comparação, utilizou-se a cepa "C" do mesmo parasito, por ser também acistogênica, proveniente do Departamento de Protozoologia do Instituto Oswaldo Cruz/Fiocruz.

Para obtenção de massa antigênica, o equivalente a $10^{6}$ taquizoítos em $0,5 \mathrm{ml}$ de exsudato peritoneal, foram inoculados por via intraperitoneal em 75 camundongos albinos, sendo 25 animais para as amostras coração e cérebro e cepa "C", respectivamente.

\footnotetext{
"Parte da tese de mestrado do primeiro autor junto ao Curso de Pós-graduação em Microbiologia Veterinária, UFRRJ.

“Departamento de Parasitologia Animal, Instituto de Biologia, Universidade Federal Rural do Rio de Janeiro. Seropédica, RJ, Brasil, 23890-000.

-.. Curso de Pós-Graduação em Medicina Veterinária - Parasitologia Veterinária - UFRRJ.

.... Departamento de Microbiologia e Imunologia Veterinária, Instituto de Veterinária, UFRRJ.
} 


\section{Purificação do material utilizado}

O exudato obtido de cada lote foi submetido ao método de centrifugação diferencial, segundo Lycke e Lund (1964), para separação dos taquizoítos dos outros constituintes do exudato peritoneal. A seguir, utilizando-se tubos siliconizados de $50 \mathrm{ml}$, centrifugou-se o volume obtido de exudato, em centrífuga refrigerada (DPR - 6000 Centrifuge, Damond/IEC) a $65 x g$ por 5 minutos a $4^{\circ} \mathrm{C}$. O sobrenadante foi centrifugado a $440 \mathrm{xg}$ por 20 minutos a $4^{\circ} \mathrm{C}$. O "pellet" foi ressuspenso, ao volume inicial, em PBS $\mathrm{pH} \mathrm{7,2} \mathrm{e}$ centrifugado a $260 \mathrm{xg}$ por 10 minutos a $4^{\circ} \mathrm{C}$. Esse novo sobrenadante foi centrifugado a $440 \mathrm{xg}$ por 20 minutosa $4^{\circ} \mathrm{C}$. O "pellet" final foi ressuspenso, ao volume inicial em PBS $\mathrm{pH} 7,2$. O produto dessa centrifugação final foi submetido ao exame de microscopia óptica, para confirmar a pureza da suspenção de taquizoítos livres, após o qual, procedeuse à contagem dessas formas parasitárias, de cada lote, em câmara de Neubauer (Tabela 1).

Tabela 1: Contagem de taquizoítas e dosagem de proteínas das amostras e da cepa de Toxoplasma gondii estudadas.

\begin{tabular}{|c|c|c|c|}
\hline & & Amostras & Cepa \\
\hline & Cérebro & Coração & Congênita \\
\hline${ }^{\star}$ Taquizoítas & $1,6 \times 10^{8}$ & $1,5 \times 10^{8}$ & $2,1 \times 10^{8}$ \\
\hline **Proteína $(\mathrm{mg} / \mathrm{ml})$ & 2,64 & 1,05 & 2,22 \\
\hline
\end{tabular}

* Total de taquizoítas por ml após centrifugação diferencial.

** Determinação de proteína segundo método de Lowry et al. (1951).

\section{Sonicação e dosagem protéica}

A suspensão de células foi submetida à sonicação sob banho de gelo com um sonicador (Sonic Dismembrator Model 300, Fisher) a $60 \mathrm{Hertz}$, em intervalos de 5 minutos por 30 minutos. Após sonicação, o material foi submetido ao exame de microscopia óptica para certificar o rompimento total dos taquizoítos. A seguir, submeteu-se o preparado a dosagem de proteínas, utilizando-se o método do reagente de Folin, segundo metodologia descrita por Lowry et al. (1951), cujos valores também se encontram na Tabela 1. Finalmente, o material a ser analisado foi dividido em alíquotas de $2,0 \mathrm{ml}$ em tubos tipo "eppendorf" e estocado a $-20^{\circ} \mathrm{C}$.

\section{Eletroforese em gel de SDS - poliacrilamida}

Os extratos protéicos foram submetidos ao tratamento em tampão para eletroforese a saber: DTT (Dithiothreitol), SDS (Dodecil sulfato de sódio), Tris-HCl, glicerol, BFB (Azul de bromo fenol) e em seguida desnaturado a $100^{\circ} \mathrm{C}$ por 3 minutos.

A eletroforese em sistema descontínuo (Andrews, 1981) foi realizada em gel de SDS - poliacrilamida a 10\% (SDS - PAGE) com proporção acrilamida - bis acrilamida 30:1; utilizando cuba vertical (Mini protean II, Bio Rad Laboratories), fonte (2297 Macrodrives 5 constant power suply, LKB Bromma) e unidade de refrigeração (2219 Multitemp II Thermostatic Circulater, LKB Bromma).

Utilizou-se $210 \mathrm{mcg}$ de extrato, sonicado total de taquizoítas de T. gondii, para cada amostra, por gel. A eletroforese foi realizada a 80 Volts, $25 \mathrm{~mA}$ e 15 Watts a $4^{\circ} \mathrm{C}$, para o empilhamento da amostra; posteriormente a corrida foi realizada a $100 \mathrm{~V}, 25 \mathrm{~mA}, 15 \mathrm{~W}$ a $4^{\circ} \mathrm{C}$ por uma hora e 40 minutos, para separação das proteínas. Após a corrida, o gel foi fixado em solução de metanol a $50 \%$ por 30 minutos à temperatura ambiente. Corado pelo azul briIhante de Comassie 250R (Bio Rad Laboratories) por 30 minutos a temperatura ambiente. Descorado com solução ácido acético-metanol até a total revelação dos zimogramas. Seco em solução de ácido acético-metanolformaldeído por 30 minutos à temperatura ambiente e, montado em papel celofane poroso (LKB Bromma), para posterior análise dos zimogramas.

As proteínas foram analisadas conforme mobilidade relativa no zimograma, tendo como parâmetro a curva de calibração de um padrão de peso molecular (Sigma Chemical) contendo alfa-lactoalbumina $(14,2 \mathrm{Kd})$, tripsinogênio $(24 \mathrm{Kd})$, anidrase carbônica $(29 \mathrm{Kd})$, gliceraldeído 3-fostato desidrogenase (36 Kd), ovoalbumina $(45 \mathrm{Kd})$, soro albumina bovina $(66 \mathrm{Kd}) \mathrm{e}$ fosforilase b (97,4 Kd) (Fig. 1).

Figura 1: Curva de calibração do padrão de peso molecular conforme mobilidade eletroforética no gel de SDS-poliacrilamida a $10 \%$

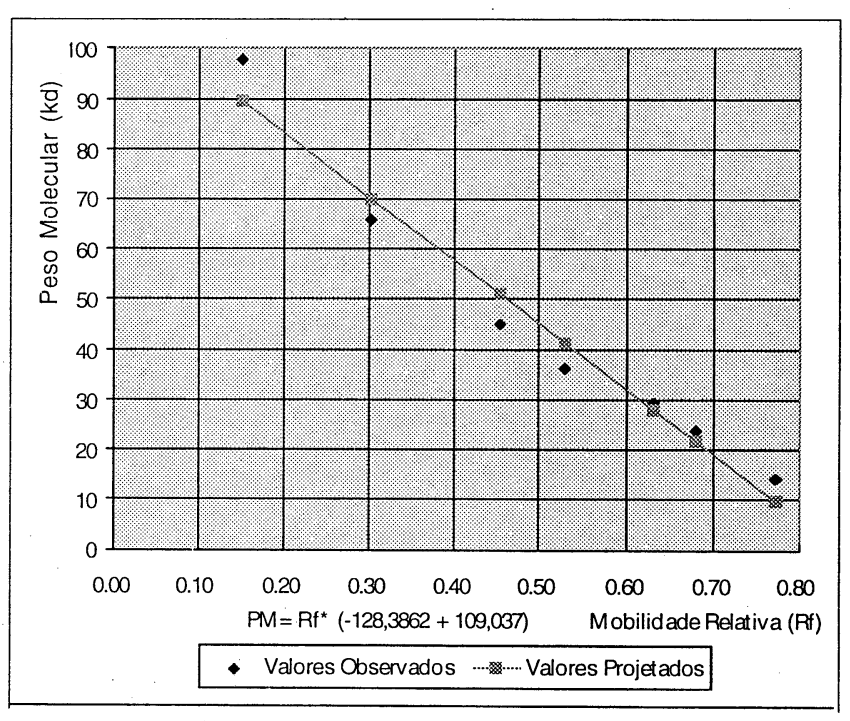

\section{Densitometria}

Após a montagem dos géis, integrou-se os zimogramas por densitometria a laser, utilizando-se um densitômetro (2202 Ultroscan laser densitometer, LKB Bromma) acoplado a um registrador de picos (Integrator 3396 série II, Hewlett Packard), a fim de analisar as bandas de proteínas e suas respectivas áreas (concentrações), para cada amostra. 


\section{Resultados e discussão}

A análise eletroforética no presente estudo revelou que os perfis dos extratos protéicos de taquizoítas das amostras cérebro e coração e, da cepa "C" diferem entre si (Tabela 2). Apesar do grupo analisado terem compartilhado identicamente oito moléculas (P30; 34,7; 43; 50; 58; 67; 80 e P97). Esses dados revelaram a existência de diferença intraespecífica entre as amostras isoladas de galinha infectada naturalmente, assim como essas com a cepa "C" (Fig. 2).

A fim de caracterizar os perfis protéicos dos grupos de $T$. gondii estudado, procedeu-se à eletroforese em gel de SDS - poliacrilamida (SDS-PAGE), em sistema descontínuo, por este apresentar melhor resolução do zimograma (Sargent e George, 1975). Este método tem

Tabela 2: Perfis eletroforéticos e concentrações protéicas das bandas nos zimogramas dos extratos de taquizoítas de Toxoplasma gondii.

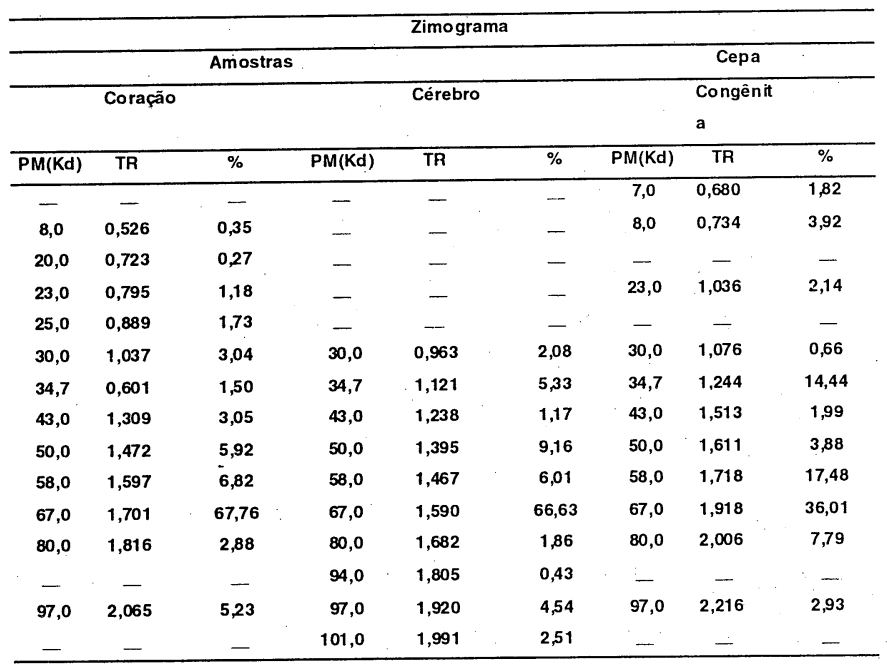

PM (Kd). Peso molecular aproximado em kilodaltons.

TR. Tempo de retenção.

$\%$. Concentração protéica. sido utilizado para diferenciar vários grupos de microrganismos, entre eles: vírus, bactérias, fungos e protozoários (Andrews, 1981). A caracterização fenotípica e genotípica do $T$. gondii tem sido amplamente estudadas através da eletroforese, como também a expressão desse parasita no sistema hospedeiro (Bloomfield e Remington, 1970 ; Sibley e Boothroyd, 1992 ; Guo e Johnson, 1995).

Diferenças de perfis protéicos de $T$. gondiitêm sido descritas para cepas isoladas em vários hospedeiros, como também de amostras intraespecíficas (Bloomfield e Remington, 1970; Frenkel, 1990; Sibley e Boothroyd, 1992), sendo algumas dessas amos-traspouco patogênicas para seu hospedeiro natural, como foi observado por Peixoto e Lopes (1990) em camundongos, de uma amostra cistogênica isolada de galinhas com infecção natural.

Muitas amostras de T. gondii têm sido isoladas em diferentes hospedeiros. Embora com morfologia semelhante, têm-se observado variações a nível biológico, sorológico e imunológico (Ware e Kasper, 1987 ; Verhofstede et al., 1988 ; Charif et al., 1990). Além da inespecificidade de parasitismo, a caracterização deste protozoário deve ser feita tomando-se o cuidado de não confundí-lo com outros coccídios, principalmente com Neospora caninum, que se assemelha às formas do T. gondii, a microscopia óptica e compartilhem algumas moléculas (P17, P29 e P30) de mesma origem e peso molecular (Bjerkas et al., 1994).

A virulência das amostras de $T$. gondiitem sido evidenciada pelo seu efeito sobre camundongos (Kaufman et al., 1958); entretanto, a caracterização antigênica (protéica) é melhor identificada pelo perfil eletroforético (Bloomfield e Remington, 1970 ; Charif et al., 1990). As variações nas concentrações de proteínas vêm corroborar com as características de virulência e antigenicidade das amostras de T. gondii, como observado por Santoro et al. (1985).

As variações protéicas aqui evidenciadas foram justificadas, pois cepas de $T$. gondii isoladas de vários
Figura 2: Análise de proteínas (concentração) de taquizoítas do Toxoplasma gondii: Área integrada por densitometria da amostra cérebro $(A)$, amostra coração $(B)$ e da cepa congênita $(C)$.

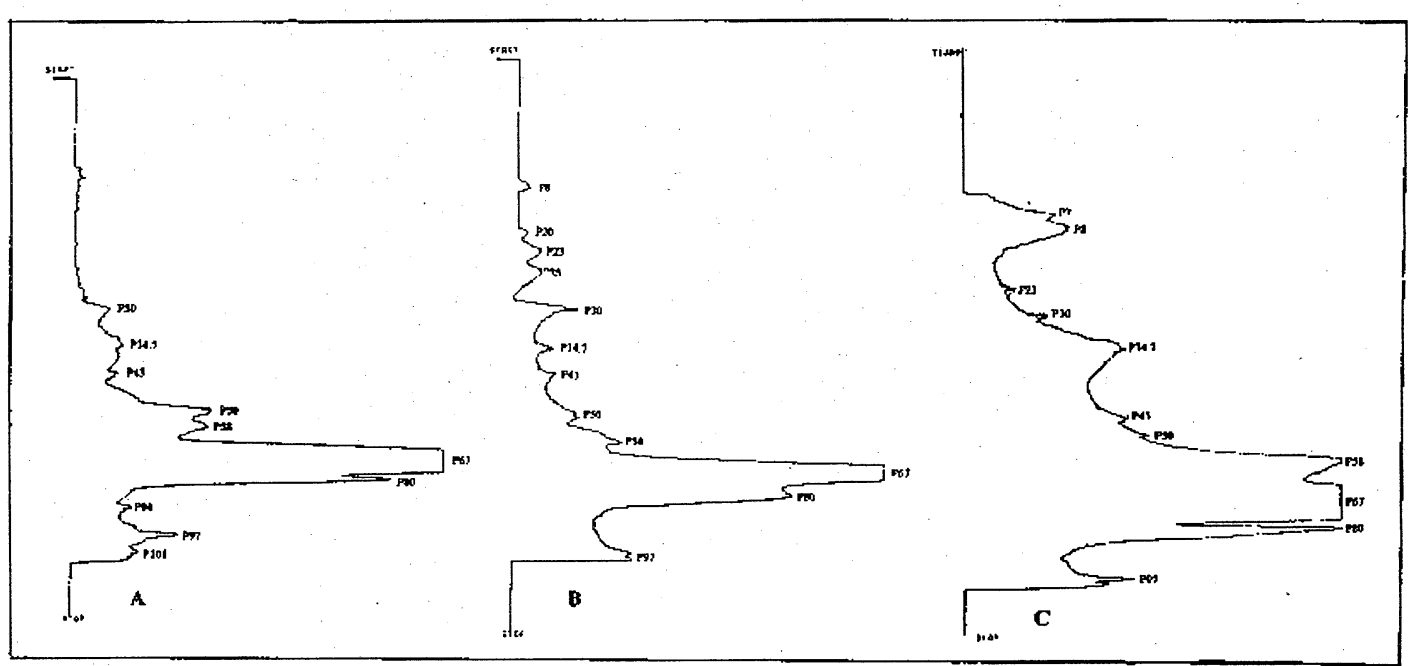


hospedeiros apresentam virulência e antigenicidade distinta, sendo estas associadas às características fenotípicas, embora possuam a mesma identidade genotípica (Ware e Kasper, 1987 ; Sibley e Boothroyd, 1992 ; Guo e Johnson, 1995).

Quanto à densitometria, pôde-se observar que as proteínas reveladas no gel de SDS - poliacrilamida, mostraramse sensíveis, apresentando picos compatíveis coma eletroforese (Fig. 2). A análise das bandas de proteína nos zimogramas foram realizadas por densitometria alaser, a fim de certificar-se o grau de pureza dos extratos antigênicos de $T$. gondii e as respectivas concentrações das bandas (Andrews, 1981).

A concentração protéica de cada banda dos zimogramas, integrados em áreas, mostraram-se distintas. As diferenças apresentadas podem ser consideradas pertinentes, uma vez que partiu-se da mesma concentração de proteína para cada preparação de extrato de $T$. gondii. Ao se comparar as proteínas compartilhadas entre as amostras, pôde-se verificar diferenças entre as concentrações de cada molécula (Tabela 2). Essas variações podem estar associadas à virulência do
T. gondii para camundongos albinos, como foi observado por Kaufman et al. (1958). Flausino (1996) correlacionou as variações protéicas e suas concentrações com o poder invasivo dos taquizoítas do $T$. gondii para macrófagos peritoneais de camundongos submetidos a infecçã̃o.

Nesse estudo o material analisado é proveniente de $T$. gondii acistogênico, embora Kasper et al. (1982) tenha observado que a cepa "RH" acistogênica era desprovida de proteína de membrana como a P22; no presente estudo constatou-se que algumas proteínas de superfície de membrana, como a P30 e P34,7, encontravam-se em todo material analisado e outras, na amostra coração (Tabela 2). Além disso, ainda se pôde observar variações quanto à concentração de proteínas de $T$. gondii em diferentes cepas, como o observado por Santoro et al. (1985) para P30, com participação no total de proteínas contidas em extrato deste parasito com variação de 3-5\%, o que não foi observado neste estudo, onde essa proteína teve valores baixos. As variações intraespecíficas observadas sugerem uma possível adaptação do parasita ao hospedeiro.

\begin{abstract}
Proteic changes in tachyzoites of an acystogenic isolates of Toxoplasma gondii were studied and compared to congenital strain which has been maintened in albino mice. These isolates were obtained from a naturally infected chiken. Eletrophoresis evaluation reveled distinct proteic autlines, although the group shares eight molecule (P30; 34,7; 43; 50; 58; 67; 80 and P97). Densitometry analysis reveled outlines compatible with eletrophoresis. There were also differences at levels the proteics concentrations of every molecule. The proteic variations observed suggested a possible parasitichost adaptation.
\end{abstract}

Keywords: Toxoplasma gondii; albino mice; chiken isolates; tachyzoites; congenital strain.

\title{
Agradecimentos
}

Ao Dr. Ivo Baldani do Laboratório de Bioquímica, Centro Nacional de Pesquisa de Agrobiologia-EMBRAPA e a Jean Luiz Simões de Araújo, Mestrando do Curso de Pós-Graduaçào em Ciências do Solo-UFRRJ, pelo apoio laboratorial. Ao Dr. Wilson Jacinto da Silva Souza do Departamento de Protozoologia do Instituto Oswaldo Cruz-Fiocruz, pela cessão da cepa cọngênita de T. gondii para o estudo comparativo.

\section{Referências bibliográficas}

ANDREWS, A. T. Eletrophoresis : theory, techniques, and biochemical and clinical applications. Oxford Clarendon Press, 1981.M onographs on Physical Biochemistry.

BJERKÂS, I., JENKINS, M. C., DUBEY, J. P. Identification and characterization of Neospora caninum tachyzoite antigens useful for diagnosis of neosporosis. Clin. Diag. Lab. Immunol., v. 1, p. 214-221, 1994.

BLOOMFIELD, M. M., REMINGTON, J. S. Comparison of three strains of Toxoplasma gondii by polyacrilamide-gel eletrophoresis. Trop. Geogr. Med., v. 22, p. 367-370, 1970.
CHARIF, $\mathrm{H}$. et al. Toxoplasma gondii : characterization and localization of antigens secreted from tachyzoites. Exp. Parasitol., v. 71, p. 114-124, 1990.

DECOSTER, A., DARCY, F., CAPRON, A. Recognition of Toxoplasma gondii excreted and secreted antigens by human sera from acquired and congenital toxoplasmosis: identification of markers of acute and cronic infection. Clin. Exp. Immunol., v. 73, p. 376-382, 1988.

DUBEY, J. P., MILLER, N. L., FRENKEL, J. K. Characterization of the new fecal form of Toxoplasma gondii oocyst from cat feces. J. Exp. Med., v. 132, p. 636-662, 1970. 
FLAUSINO, W. Caracterização fenotípica de taquizoítos peritoneais de Toxoplasma gondii Nicolle \& Manceaux, 1909 (Apicomplexa: Toxoplasmatinae) isolados de uma galinha naturalmente infectada frente a cepa congênita. 1996. 65 f. Dissertação (Mestrado) - Universidade Federal Rural do Rio de Janeiro, 1996.

FRENKEL, J. K. Toxoplasmosis : parasite life cycle, pathology, and immunity. In: HAMMOND, D. M., LONG, P. L. The coccidia. Baltimore University Park Press, 1972. p. 343-410.

FRENKEL, J. K. Transmission of toxoplasmosis and the role of immunity in limiting transmission and illness. J. Am. Vet. Med. Assoc., v. 196, p. 233-240, 1990.

GUO, Z. G., JOHNSON, A. M.. Genetic caracterization of Toxoplasma gondiistrains by random amplified polymorphic DNA polymerase chain reaction. Parasitology, v. 111, p. 127132, 1995.

KASPER, L. H., CRABB, J. H., PFEFFERKRON, E. R. Isolation and characterization of a monoclonal antibody resistent antigenic mutant of Toxoplasma gondii. J. Immunol., v. 129, p. 1694-1699, 1982.

Purification of a major membrane protein of Toxoplasma gondii by immunoabsorption with a monoclonal antibody. J. Immunol., v. 130, p. 2407-2412, 1983.

KAUFMAN, H. E., REMINGTON, J. S., JACOBS, L.. Toxoplasmosis : the nature of virulence. Am. J. Ophthalmol., v. 46, p. $255-261,1958$.

LOWRY, O. H., ROSEBROUGH, N. J., FARR, A. L., RANDALL, R. J. Protein measurement with the folin phenol reagent. $J$. Biol. Chem., v. 193, p. 265- 275, 1951.
LYCKE, E., LUNDE, E.. A tissue culture method for titration of infective and determination of growth rate of Toxoplasma gondii. Acta Pathol. Microbiol. Scand., v. 60, p. 209-220, 1964.

MEDEIROS, S. M., LOPES, C. W. G. Pleomorfismo de uma amostra acistogênica de Toxoplasma gondii Nicolle \& Manceaux, 1909 (Apicomplexa: Toxoplasmatinae) isolada de uma galinha naturalmente infectada. Rev. bras. Med. Vet., v. 18, p. 71-73, 1996.

PEIXOTO, C. M. S., LOPES, C. W. G. Isolamento do Toxoplasma gondii Nicolle \& Manceaux, 1909 (Apicomplexa: Toxoplasmatinae) em galinhas naturalmente infectadas. Arq. Univ. Fed. Rur., Rio de Janeiro, v. 13, p. 105-111, 1990.

RUIZ, A., FRENKEL, J. R. Intermediate and transport hosts of Toxoplasma gondii in Costa Rica. Am. J. Trop. Med. Hyg., v. 29, p. 1161-1166, 1980.

SANTORO, F. et al. Serodiagnosis of toxoplasma infection using a purified parasite protein (P30). Clin. Exp. Immunol., v. 62, p. 262-269, 1985.

SARGENT, J. R., GEORGE, S. G. Methods in zone eletrophoresis. Poole. [England] BDH Chemicals Ltd. 1975. 219 p.

SIBLEY, L. D., BOOTHROYD, J. C. Virulent strains of Toxoplasma gondii comprise a single clonal lineage. Nature, v. 359, p. 82-85, 1992.

WARE, P. L., KASPER, K. H. Strain-specific antigens of Toxoplasma gondii. Inf. Immun., v. 55, p. 778-783, 1987.

VERHOFSTEDE, C., VAN GELDER, P., RABAEY, M. The infectionstage-related IgG response to Toxoplasma gondii studied by immunoblotting. Parasitol. Res., v. 74, p. 516-520, 1988.

\section{Você acaba de ganhar uma equipe de assistentes internacionais.}

Agora você vai tratar muito melhor dos cães e gatos sob seus cuidados, pois acaba de chegar ao E Brasil a linha WALTHAM VETERINARY DIETS.

Desenvolvida na Inglaterra pelo Centro de Pesquisas Waltham, maior autoridade mundial no

đ̋ cuidado e nutrição de animais de estimação, a linha possui alimentos extremamente palatáveis

de alta digestibilidade, formulados para auxiliar no controle e tratamento de:

Insuficiência renal crônica de câes e gatos (Low Protein Diet);

Obesidade de cães e gatos (Calorie Control Diet);

$\sum$ Hipersensibilidade alimentar de câes e gatos (Selected Protein Diet);

Enfermidades do trato digestivo de cães (Low Fat Diet);

Determinadas patologias do trato urinário inferior de gatos (Control Phormula Diet).

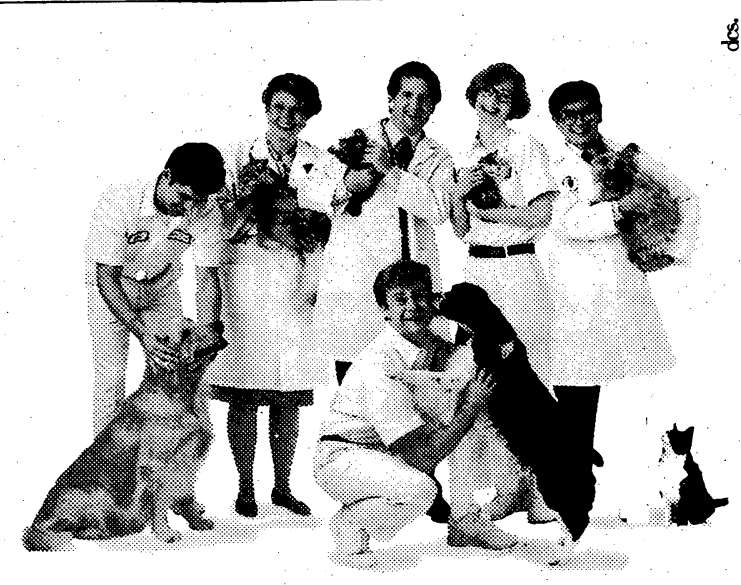

